\title{
ON STABILITY AND HYPERSTABILITY OF AN EQUATION CHARACTERIZING MULTI-ADDITIVE MAPPINGS
}

\author{
ANNA BAHYRYCZ \\ AGH University of Science and Technology, Faculty of Applied Mathematics \\ Mickiewicza 30, 30-059 Kraków, Poland \\ E-mail: bahyrycz@agh.edu.pl
}

\begin{abstract}
In this paper, using the fixed point approach, we prove some stability and hyperstability results for an equation characterizing multi-additive mappings. Our results generalize some known outcomes. In particular, we give a solution of a problem concerning optimality of some estimations. Key Words and Phrases: Multi-additive mapping, Hyers-Ulam stability, hyperstability, fixed point theorem.
\end{abstract}

2010 Mathematics Subject Classification: 39B52, 39B55, 47H10.

\section{REFERENCES}

[1] T. Aoki, On the stability of the linear transformation in Banach spaces, J. Math. Soc. Japan, $\mathbf{2}(1950), 64-66$

[2] D.G. Bourgin, Approximately isometric and multiplicative transformations on continuous function rings, Duke Math. J., 16(1949), 385-397.

[3] D.G. Bourgin, Classes of transformations and bordering transformations, Bull. Amer. Math. Soc., 57(1951), 223-237.

[4] J. Brzdęk, Hyperstability of the Cauchy equation on restricted domains, Acta Math. Hungar., 141(2013), 58-67.

[5] J. Brzdęk, J. Chudziak, Zs. Páles, A fixed point approach to stability of functional equations, Nonlinear Anal., 74(2011), 6728-6732.

[6] J. Brzdęk, K. Ciepliński, Hyperstability and superstability, Abstr. Appl. Anal., 2013(2013), Article ID 401756, $13 \mathrm{pp}$

[7] K. Ciepliński, Generalized stability of multi-additive mappings, Appl. Math. Lett., 23(2010), $1291-1294$.

[8] K. Ciepliński, Stability of multi-additive mappings in $\beta$-Banach spaces, Nonlinear Anal., 75(2012), 4205-4212.

[9] P. Găvruța, A generalization of the Hyers-Ulam-Rassias stability of approximately additive mappings, J. Math. Anal. Appl., 184(1994), 431-436.

[10] D.H. Hyers, On the stability of the linear functional equation, Proc. Nat. Acad. Sci. U.S.A., 27(1941), 222-224.

[11] M. Kuczma, An Introduction to the Theory of Functional Equations and Inequalities. Cauchy's Equation and Jensen's Inequality, Birkhäuser Verlag, Basel, 2009.

[12] Gy. Maksa, Zs. Páles, Hyperstability of a class of linear functional equations, Acta Math. Acad. Paedag. Nyìregyháziensis, 17(2001), 107-112. 
[13] W.-G. Park, J.-H. Bae, On the solution of a multi-additive functional equation and its stability, J. Appl. Math. Comput., 22(2006), 517-522.

[14] W.-G. Park, J.-H. Bae, Solution of a vector variable bi-additive functional equation, Commun. Korean Math. Soc., 23(2008), 191-199.

[15] W.-G. Park, J.-H. Bae, Stability of a bi-additive functional equation in Banach modules over a $C^{*}$-algebra, Discrete Dynam. Nat. Soc., 2012(2012), Article ID 835893, 12 pp.

Received: February 11, 2015; Accepted: October 30, 2015. 